\title{
Agricultura urbana e Segurança Alimentar e Nutricional:
}

conceitos, contextos e possíveis intersecções

\section{Urban agriculture and food and nutrition security:}

concepts, contexts, and possible intersections

\section{Vanessa Daufenback ${ }^{1}$ \\ Letícia Machado ${ }^{2}$}

Claudia Maria Bógus ${ }^{3}$

Nas últimas décadas, instituições como a FAO [Organização das Nações Unidas para a Alimentação e a Agricultura] vêm justificando a prática da agricultura urbana (AU) como uma atividade fundamental para superação da fome e da miséria. No Brasil foi elaborado um Panorama sobre Agricultura Urbana e Periurbana, no qual a prática é vinculada com obtenção da Segurança Alimentar e Nutricional (SAN).

O estudo possui natureza de revisão sistemática, no qual foi utilizada a base de dados Scielo, devido à sua maior abrangência e interdisciplinaridade de publicações e temas. Optou-se por fazer uma busca por artigos latino-americanos, pensando no pioneirismo de Cuba nas ações de AU. Primeiramente, foi feita uma busca utilizando a palavra-chave "agricultura urbana", através da qual foram encontrados 156 artigos. No segundo momento, foi realizada outra seleção pensando nos títulos e nas palavras-chaves disponíveis nos documentos, chegando ao final de 32 artigos. Após o descarte de artigos que não eram latino-americanos, chegou-se a 26 artigos que faziam correlação, mesmo que primária entre AU e SAN.

Apenas 5 trabalhos fazem uma relação direta entre SAN e AU, sendo que os demais artigos apenas exploraram alguma dimensão presente neste conceito. De forma geral, os trabalhos mostraram que existe uma multiplicidade nas experiências de AU nos países latino-americanos, com destaque para o debate da sustentabilidade. Notou-se que ainda não existe uma definição concreta ao redor do que seja AU; a maioria dos estudos traz definições amplas que vão da produção de alimentos à questão ambiental. Poucos estudos levantam a problemática do agricultor urbano e da escala de produção enquanto elemento central à promoção da Segurança Alimentar e Nutricional, apesar de promover o princípio da Soberania Alimentar e Nutricional (troca de sementes, preservação de tradições de plantio). Apesar de representar uma atividade com valor simbólico-afetiva, de formação de laços comunitários e promoção de saúde, a maioria dos estudos aponta algumas problemáticas importantes: contaminação do cultivo por metais pesados, dificuldades para atingir sustentabilidade ambiental, social e econômica, principalmente para agricultores, que acabam por trabalhar em outros setores; ausência de assistência técnica permanente e de inclusão social dos agricultores, em sua maioria migrantes vulneráveis de regiões rurais, residindo em áreas de grande vulnerabilidade. Essa amplitude pode explicar a não formalização de um conceito para agricultura urbana, que é entendido como um conceito aberto que pode trazer vários significados. Conclui-se 
que poucos estudos analisam a vinculação entre AU e SAN, mesmo no Brasil, onde o direito humano à alimentação adequada é um direito constitucional. Em geral, a agricultura urbana é vinculada à sustentabilidade ambiental, na criação de cidades mais verdes melhorando a qualidade de vida de seus habitantes.

Palavras-chave: agricultura urbana; segurança alimentar e nutricional; soberania alimentar e nutricional; direito humano à alimentação adequada.

Keywords: urban agriculture; food and nutrition security; food and nutritional sovereignty; human right to adequate food.

1 Doutoranda em Saúde Pública pela Universidade de São Paulo.

2 Mestranda em Saúde Pública pela Universidade de São Paulo.

${ }_{3}$ Professora associada pelo Departamento de Política, Cestão e Saúde da Universidade de São Paulo. 